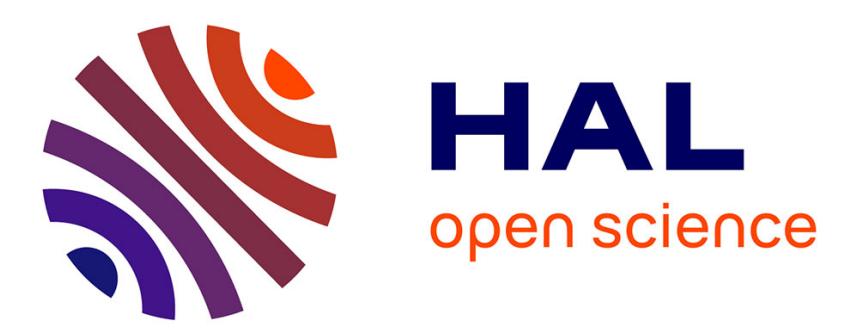

\title{
Note complémentaire à propos d'une inscription du tympan de la cathédrale de Jaca ( Aragon) (note d'information)
}

Robert Favreau

\section{- To cite this version:}

Robert Favreau. Note complémentaire à propos d'une inscription du tympan de la cathédrale de Jaca ( Aragon) (note d'information). Comptes-rendus des séances de l'Académie des inscriptions et belles-lettres, 2004, 148 (1), pp.7-10. 10.3406/crai.2004.22685 . halshs-03199251

\section{HAL Id: halshs-03199251 \\ https://shs.hal.science/halshs-03199251}

Submitted on 15 Apr 2021

HAL is a multi-disciplinary open access archive for the deposit and dissemination of scientific research documents, whether they are published or not. The documents may come from teaching and research institutions in France or abroad, or from public or private research centers.
L'archive ouverte pluridisciplinaire HAL, est destinée au dépôt et à la diffusion de documents scientifiques de niveau recherche, publiés ou non, émanant des établissements d'enseignement et de recherche français ou étrangers, des laboratoires publics ou privés. 


\section{Note complémentaire à propos d'une inscription du tympan de la} cathédrale de Jaca ( Aragon) (note d'information)

\section{Robert Favreau}

\section{Citer ce document / Cite this document :}

Favreau Robert. Note complémentaire à propos d'une inscription du tympan de la cathédrale de Jaca ( Aragon) (note d'information). In: Comptes rendus des séances de l'Académie des Inscriptions et Belles-Lettres, 148 ${ }^{\mathrm{e}}$ année, N. 1, 2004. pp. 7-10;

doi : https://doi.org/10.3406/crai.2004.22685

https://www.persee.fr/doc/crai_0065-0536_2004_num_148_1_22685

Fichier pdf généré le 27/11/2018 


\title{
NOTE D'INFORMATION
}

\author{
NOTE COMPLÉMENTAIRE \\ À PROPOS D'UNE INSCRIPTION DU TYMPAN \\ DE LA CATHÉDRALE DE JACA (ARAGON), \\ PAR M. ROBERT FAVREAU, CORRESPONDANT DE L'ACADÉMIE
}

Le tympan roman de la cathédrale de Jaca en Aragon présente un chrisme accolé de l'alpha et de l'oméga et entouré de deux lions. Le lion de gauche qui épargne un homme étendu à terre est la figure du Christ miséricordieux pour le pécheur :

«le lion sait épargner celui qui est étendu à terre, et le Christ celui qui l'implore »;

le lion de droite, qui maîtrise un ours et un basilic, est le symbole de la Résurrection :

«il est le lion fort, qui foule aux pieds l'empire de la mort. »

Une troisième inscription, à la base du tympan, adresse une exhortation morale au lecteur :

"Si tu cherches à vivre, toi qui es tenu par la loi de la mort, viens ici en suppliant, renonçant aux nourritures empoisonnées. Purifie ton cœur de ses vices, afin de ne pas mourir d'une seconde mort. "

L'inscription qui entoure le chrisme fait référence à la Trinité. Son deuxième vers, d'une compréhension difficile, a fait l'objet d'une vingtaine d'études, avec des interprétations qui n'étaient pas ou pas pleinement satisfaisantes. Dans une communication présentée ici même en $1996^{1}$, j'ai montré que dans le chrisme accolé de l'alpha et de l'oméga il fallait prendre les lettres grecques XP et A en leur donnant la valeur des lettres latines, pour former le mot PAX. $P$ est le Père, $A$ est le Fils, qui dans l'Apocalypse est dit l'alpha et l'oméga, le commencement et la fin, $X$, lettre «double» comme le dit Isidore de Séville, est l'Esprit Saint, qui procède du Père et du Fils.

1. R. Favreau, «Les inscriptions du tympan de la cathédrale de Jaca », CRAI. 1996, p. $536-560$ 
+ HAC IN SCULPTURA, LECTOR, SI GNOSCERE CURA,

$P$ PATER, A GENITUS, DUPLEX EST SPIRITUS ALMUS.

HI TRES JURE QUIDEM DOMINUS SUNT UNUS ET IDEM.

«En cette sculpture prends soin de reconnaître, lecteur, que $P$ est le Père, A le Fils, la [lettre] double l'Esprit Saint.

Ces trois sont à juste titre un seul et même Seigneur. »

$\mathrm{Au} \mathrm{x}^{\mathrm{e}}$ siècle Atton, évêque de Verceil, a commenté un passage de l'épître aux Éphésiens $(2,4)$ :

Ipse enim est pax nostra

«Il est, en effet, notre paix »,

en présentant cette interprétation du mot pax, et en soulignant que ce pax est formé de trois lettres comme la Trinité est formée de trois personnes qui forment un seul et même Dieu.

Or en préparant une étude sur l'expression rex, lex, lux, pax appliquée au Christ, j'ai été conduit par une note d'un article de Bernhard Bischoff sur « la croix et le livre au haut Moyen Âge et dans les premiers siècles de la Reconquista espagnole $»^{2}$ à me reporter au De sobrietate que Milon, moine de Saint-Amand $(\dagger 872)^{3}$, dédia au roi Charles le Chauve. Dans une dizaine de vers, au livre II, Milon commente, lui aussi, le passage de la lettre aux Éphésiens, «Je suis votre paix ». Le mot «paix (pax)» unit des lettres qu'une simple syllabe divise. Elles sont trois parce qu'il $\mathrm{y}$ a trois personnes dans une seule essence. Trois noms sont disposés pour les trois lettres, $P$ le Père, qui ne reçoit pas d'ailleurs son être, $A$ désigne le Fils, que le grec nomme alpha ( Moi je suis le premier dans le verbe, et je suis le dernier, $\Omega$, moi je suis le début $\gg^{4}$, l'$^{\prime} A$ est la première voyelle et la première lettre) et $X$ est le double, parce que l'Esprit Saint procède de l'un et de l'autre, la dernière des lettres parce que justement il revient vers les autres, semblable et égal au Père et contemporain du Fils ».

Pax apices scindit quos simplex sillaba jungit :

Hi tres sunt, quia tres personae essentia in una;

Litterulis ternis aptantur nomina terna:

2. B. Bischoff, « Kreuz und Buch in frühmittelalter und in den crsten Jahrhunderten der spanischen Reconquista ", Festgabe für Carl Wehmer, Amsterdam, 1963, p. 19-34, repris dans les Mittelalterliche Studien. Ausgewälhlte Aufsätze zur Schriftkunde und literaturgeschichte. Band II, Stuttgart. 1967, p. 284-303.

3. Histoire littéraire de la France, t. V, Paris, 1866, p. 409-416.

4. Ego sum Alfa et Omega, primus et novissimus, principium et finis (Ap. 22.13). 


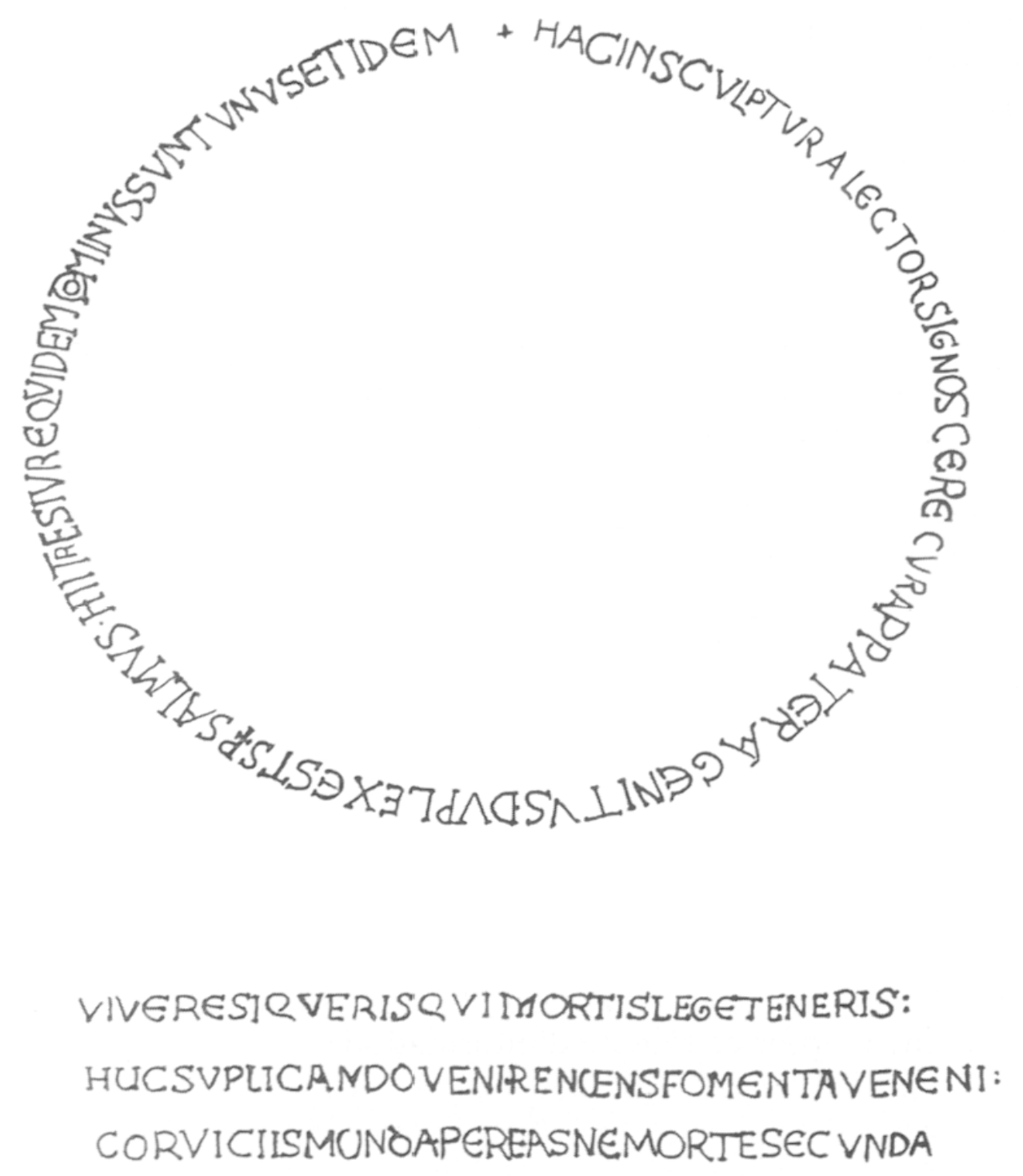

Fig. 1. - Dessin des inscriptions du tympan de Jaca (aimablement communiqué par M. Juan F. Esteban Lorente). 
$P$ patrem, qui non aliunde hoc accipit ut sit, A genitum signat, quod graecus nominat alfa ("Alfa ego sum primus sermone, novissimus $\Omega$ sum, ipse ego principium », prior a vocalis apexque est) Xque duplex, ab utroque venit quia spiritus almus, Tertia fine apicum, ad reliquos quia rite recurrit, Compar et cequalis patri natoque coavus.

L'interprétation que j'avais donnée en 1996 de l'inscription de Jaca ne change pas, mais il faut en reporter la source à Milon de Saint-Amand, qu'a recopié et développé Atton de Verceil. On trouve, en effet, à Jaca, les mots mêmes de Milon :

P PATER, A GENITUS, DUPLEX EST SPIRITUS ALMUS

d'un côté,

$P$ patrem, A genitum, duplex... spiritus almus

de l'autre. L'emprunt est d'autant plus évident qu'il s'agit de textes métriques, et que par exemple on n'aurait pu écrire Spiritus sanctus qui aurait empêché d'avoir un dactyle au $5^{\mathrm{c}}$ pied. Voir en Milon de Saint-Amand la source de l'inscription de Jaca conduit du même coup à établir que le $D e$ sobrietate était connu au $\mathrm{XI}^{\mathfrak{c}}$ siècle à Jaca, mais pas nécessairement le Commentaire sur la lettre aux Éphésiens d'Atton de Verceil. L'interprétation de lettres grecques du chrisme accolé de l'alpha et de l'oméga pour en faire le mot latin pax a pu être confortée par la vogue de l'expression rex, lex, lux, pax appliquée au Christ ${ }^{6}$, qui se rencontre dans une série de chrismes du Sud-Ouest de la France, et dans des miniatures du Commentaire de l'Apocalypse de Beatus de Liebana.

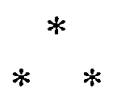

MM. Pierre Toubert, Jean-Pierre Callu et Jean-Pierre MahÉ interviennent après cette note d'information.

5. Poetae latini aevi carolini, t. III, éd. L. Traube, Berlin, 1896 (M.G.H. Poetarum latinorum Medii Aevi, III), p. 659-660. Dans une note, léditeur avoue : memini me eandem explicationem apud scriptorem ecclesiaticum legisse, sed ipsum locum nequeo reperire. II s'agit très certainement d'Atton de Verceil...

6. R. Favreau, «Rex, lex, liax, pax. Jeux de mots et jeux de lettres dans les inscriptions médiévales ". Bibliothèque de l'Ecole des chartes, t. 161, 2003, p. 625-635. 